\title{
How to Measure Digital Literacy? A Case of Croatian Adult Learners
}

\author{
Dario Pavić \\ Department for Croatian Studies, University of Zagreb, Croatia \\ dpavic@hrstud.hr \\ Iva Černja \\ Department for Croatian Studies, University of Zagreb, Croatia \\ icernja@hrstud.hr
}

\begin{abstract}
Summary
This study aims to present the rationale, the instrument and the main findings of the assessment of digital literacy of adult learners in Croatia, as a part of the project Implementation of EU Agenda for Adult Learning 2017-2019, by Ministry of Science and Education. The concept of digital literacy is at the heart of EU development policies and encompasses skills, competences, and dispositions for using a wide range of technologies, from personal computers to smartphones, vending machines, and ATMs. The digital technologies are also being used for different purposes (work, leisure, communication, health, news, etc.) and differently by social groups (by age, gender socioeconomic status, etc.). Thus, testing digital literacy in the population is of great importance given the pervasiveness of digital technologies and the apparent inadequacy of self-reported measures of digital literacy. An original test was developed, testing the usage of Windows, Word, Excel, PowerPoint, internet browser and Google Maps. The test was implemented through the LimeSurvey software with the additional files available on the participant's computer desktop. The questions were devised in a way that a participant had to solve a specific problem using the specific software, thus including the cognitive component of digital literacy. The difficulty level of the questions is approximate of those of the levels "Below Level 1" and "Level 1" of PSTRE PIAAC research. Additionally, the participants answered the question about their socio-economic status, the frequency of technology usage, and their self-perception of digital skills. The test was administered to 92 attendees of the specialization and qualification programs in seven adult learning facilities throughout Croatia (Knin, Karlovac, Zagreb, Split, Čakovec, Koprivnica, and Virovitica). The results indicate relatively low levels of digital literacy of the tested sample and the different patterns of technology usage by different socio-economic groups. Also, the questionnaire's metric characteristics show that it can be successfully used for testing digital literacy outside the laboratory setting. Conclusion: The low levels of digital literacy among the adult attendees of the specialization and qualification programs implicate the need to include the digital literacy curriculum in their learning programs, according to individual needs and experiences. Also, this research is one of the very few that did not assess only the self-perceptions of the skills or test the skills in the research facility setting, but rather in the learning facilities of adult education. Since the questionnaire performed well under these circumstances, it can be modified to be implemented in multiple environments.
\end{abstract}

Key words: digital competence test, digital skills, adult education, Croatia

\section{Introduction}

Digital skills and digital literacy, in general, have been in the center of both academic interest and national and international policies, yet the reliable measures of these skills are scarce having in mind how digital technology permeates the everyday life of modern people. Part of the reason why this is so is the multitude of definitions and conceptualizations of what digital skills, digital competence, and digital literacy are. Presenting a thorough review of the development of these concepts lies outside of the scope of this paper, yet some historical and conceptual points are in place to show why measuring digital skills has been a difficult endeavor. 
Historically, Martin and Grudziecki (2006) point that computer, IT or ICT literacy has been identified as a need as early as the late 1960s, and divide the evolution of these concepts in three phases; from the emphasis on technical knowledge on how computers operate in the earliest phase, to the critical and reflective evaluation of information technologies in the post-1990s period (Martin, Grudziecki, 2006). Also, several related concepts used during the formative years of digital technologies (e.g. media literacy, ICT literacy, computer literacy, visual literacy) coalesced in one nowadays ubiquitous concept of "digital literacy", especially from the 1990s (Chinien, Boutin, 2011), popularized by Paul Glister's seminal book "Digital literacy" (Gilster, 1997). In his definition, Gilster emphasizes the cognitive and life-related aspects of digital literacy as "[the] ability to understand and use information in multiple formats from a wide range of sources [...]" (Gilster, 1997: 1-2).

Over time, the other definitions of digital literacy have also embraced the cognitive aspect of literacy as a leading one and have conceived digital literacy as a multidimensional concept. Regardless of whether the definition is of digital literacy, digital competence or digital skill, most of them involve technical operation, but also the information management, collaboration, communication and sharing, creation of content and knowledge, ethics and responsibility, and evaluation and problem solving (Ferrari, 2012). These definitions also include the use of different digital tools and technologies, different domains of learning, and different modalities and goals of technology use (Ferrari, 2012). It must be pointed out that the terms "literacy", "competence" and "skills" are not synonyms. "Skills" are a specific and measurable application of knowledge to attain a goal, so in a digital area, it can be e.g. to open an attachment to the e-mail. "Competence" is a wider concept than "skill" (Rychen, Tiana, 2004, in Halász, Michel, 2011), and it combines knowledge (European Parliament and the Council of the European Union, 2006), skills and attitudes. "Digital literacy" is an over-reaching concept different from the "competence" by being situationally embedded (Martin, 2008). For an extensive review of the definitions of these concepts see (Chinien, Boutin, 2011).

Most of the research on the assessment of digital literacy has been focused on people's self-perception of the skills (Hargittai, 2005), especially until the mid-2000s. Although Hargittai (2005) posits that self-reported measures under certain circumstances can be used as indicators of people's real digital literacy, other studies present a series of problems regarding self-reported measures. There is a concern that people with poor ICT skills overestimate their actual skills (Danish Technology institute, n.d., in Chinien, Boutin, 2011). This overestimation of actual skills has also been shown on a small sample of US university students (Merritt, Smith, Renzo, 2005), and university students in Denmark, Finland, Germany, India, and Singapore (ECDL Foundation, 2018), dispelling the myth of young "digital natives". The same patterns of overestimated self-reported skills were found in Austria and Switzerland on a sample of participants aged 15 to 65 (ECDL Foundation, 2018).

More direct measures of digital literacy have been conducted by testing the skills of participants in a real-life or simulated computer environment. Hargittai (2002) tested the information retrieval from the Internet to discover the inequalities in digital literacy between social groups, a so-called "second digital divide" (Hargittai, 2002). In a series of articles van Deursen and associates (van Deursen, van Dijk, Peters, 2011; van Deursen, van Dijk, 2014; van Deursen, van Dijk, 2008) presented the results of testing the internet skills of Dutch population, performed in university's computer laboratory. The assignments thematic issues covered governmental information, leisure-related information, and health-related ones. The most significant finding from these studies is that the construct of "Internet skills" is composed of five parts: operational, navigation information, social, creative, and mobile (A. van Deursen, Helsper, Eynon, 2016). Jara et al. (2015) used a simulated computer environment to test the students' digital skills on a theme of ecology. The students were able to use a word processor, email, spreadsheet program, and internet browser to complete the tasks. Gui and Argentin (2011) combined theoretical multiple-choice questions with operational and evaluation skill tasks carried out on a computer to test the digital skills of Italian high school students. Apart from these studies, there are numerous digital literacy assessment frameworks carried out by national or international organizations and private corporations. The most notable of these frameworks are PIAAC PS-TR, iSkills, ECDL, SAILS (review of these and other frameworks in Ferrari, 2012 and (Sparks, Katz, Beile, 2016) and ICILS (Fraillon, et al., 2014) The emerging feature of digital literacy from these studies is that it comprises of dimensions of information definition, accessing, evaluating, managing, integrating and creating, as well as from communication, problem-solving, ethical issues and technology use (Sparks et al., 2016). 
This article aims to show the usefulness of the test of digital skills made for adult learners and to present its main findings. Testing the digital skills of adult learners in Croatia is an interesting and relevant topic. Most of these learners are of lower socio-economic and educational status, females, unemployed for a long time, but willing to get a degree in vocational education. They represent a particularly vulnerable group since less educated people have lower levels of digital skills (Gui, 2007; Hargittai, 2002; van Deursen, van Dijk, 2011; van Deursen, van Dijk, 2008) and tend to use digital technology less for human capital enhancement, and more for leisure and entertainment (Hargittai, Hinnant, 2008). Furthermore, neither primary adult education in Croatia nor the adult vocational education does not include compulsory courses on digital literacy. This is expected to be changed by the newly proposed program of adult education which is still in the preparatory phase. The information gathered by this research would be invaluable to the policymakers working on the new adult education curriculum.

\section{Data and methods}

Our test of digital skills was devised specifically for the population of adult learners in Croatia. Although the contemporary notion of digital skills includes a wide variety of platforms and software, we opted for the most ubiquitous office suite of Microsoft (Word, Outlook, Excel and PowerPoint), Windows OS, Google Chrome or Mozilla Firefox web browsers and Google Maps service. The main reasons for the inclusion of these programs were their wide-spread use and their usefulness in both private and professional areas. The test itself consisted of eighteen questions, each testing a problem in one of the aforementioned programs. The difficulty of these problems was equivalent to levels "Below level 1" and "Level 1" of the PSTRE competencies of the PIAAC research (Kirsch, Yamamoto, Garber, 2013). Solving the problems on these levels involves only a small number of steps, minimal navigation between the pages and simple inference about the goal of the problem. A test folder with test files was prepared for each participant and available on each test computer. The questionnaire and the answer forms were implemented in the online survey software LimeSurvey on the server of the University of Zagreb Computer Centre (SRCE).

The problems were divided into four difficulty groups. The easier questions required little or no navigation by the participant. The participants were usually faced with a screenshot of a program file and asked to identify a key information on the screenshot (e.g. identify the number of words, font size or font type in Word), or they were asked to open a test folder and identify an information about the files in the folder (e.g. the size of the file, the number of .pdf files in the folder, etc.). The more difficult questions asked the participant to perform one or more tasks (e.g. to copy and paste some text from the Word to the answer form, to calculate auto sum in Excel, to find the address of a government body on the internet or to find the distance between two places in Google Maps). The easiest questions were marked with one point, all the way to the most difficult ones (4 points), reflecting the number of distinct steps needed for the solution to the problem. The maximum score on the test was forty. Also, the participants were surveyed on their socio-demographic characteristics, their experience in using digital technologies and self-perception of their digital skills.

The participants were included in the sample by convenience. The MZO provided the list of twentyfive active people's universities in Croatia that perform the adult education programs. The institutions were contacted by e-mail and phone to arrange the testing date. The testing was performed in seven institutions throughout Croatia (cities Knin, Karlovac, Zagreb, Split, Cakovec, Koprivnica, and Virovitica). The reasons for the exclusion of other institutions were our inability to get their response, the lack of computer classrooms on the premises and the lack of active adult education programs. The number of participants per institution ranged from five to twenty, totaling 92 participants who started and finished the test. The different adult education programs that participants were enrolled in were caretaker, CNC machine operator, shoemaker, intermediate English and German, EU funds specialist, bookkeeper, and ECDL operator. The standard ethics protocol was followed. Each participant was informed about the goal of the survey, the anonymity measures and the right to terminate the participation in the survey at any time.

All the institutions had computer classrooms furnished with desktop computers with Windows 10 OS, Microsoft Office, and internet access. the person who conducted the testing responded only to technical questions and adjusted the accessibility features of the user's interface. In the cases where 
the participant didn't possess even the basic digital skills, the survey assistant recorded the participant's answers on all the questions except those from the test itself, so the socio-demographic and other characteristics of this kind of participant remained recorded, but the test score was assigned to zero. The maximum amount of time for the whole questionnaire was 60 minutes which was not exceeded by any of the participants.

\section{Results}

Reviewing the results includes evaluating the structure and reliability of the digital skills test. To determine the level of digital skills, the results were analyzed for the overall test and individual questions. Some basic sociodemographic determinants of test performance were also examined.

The correlation matrix of 18 items of the test indicates the suitability of the matrix for the factor analysis. The value of the Kaiser Meyer Olkin (KMO) coefficient is 0.895 , which is large enough to conclude the adequacy of the matrix for the analysis (Kaiser, 1970). Bartlett's sphericity test indicates that the extra diagonal elements of the correlation matrix are statistically significantly different from zero $\left(\chi^{2}=96.502, \mathrm{df}=153, \mathrm{p}<.001\right)$. Out of 153 correlations among the items, all were statistically significant $(\mathrm{p}<0.05)$. All item-total correlations were statistically significant $(\mathrm{p}<.05)$ and ranged from .55 to .77 .

The method of dimensionality reduction was the analysis of principal components. The initial analysis extracted 4 components with characteristic root greater than 1 (characteristic roots were $8.54 ; 1.36$; 1.15 and 1.05). The first principal component has much greater characteristic root than others. The results indicate a clear single-factor structure supported by the results of the Scree test (Figure 1.). We performed principal component analysis with an only one-factor solution. The extracted component explains $47.43 \%$ of the total variance. All items on the corresponding components have saturations greater than .50. The component saturations on the first component are shown in Table 1.

Table 1. Results of analysis of principal components

\begin{tabular}{|l|l|}
\hline Question & Component Saturation \\
\hline q1 & .677 \\
\hline q2 & .547 \\
\hline q3 4 .741 \\
\hline q5 & .768 \\
\hline q6 & .777 \\
\hline q7 & .679 \\
\hline q8 & .649 \\
\hline q9 & .542 \\
\hline q10 & .762 \\
\hline q11 & .732 \\
\hline q12 & .578 \\
\hline q13 & .776 \\
\hline q14 & .687 \\
\hline q15 & .668 \\
\hline q16 & .631 \\
\hline q17 & .702 \\
\hline q18 & .694 \\
\hline Characteristic root & .719 \\
\hline \% of Variance & 8.538 \\
\hline & 47.431 \\
\hline
\end{tabular}




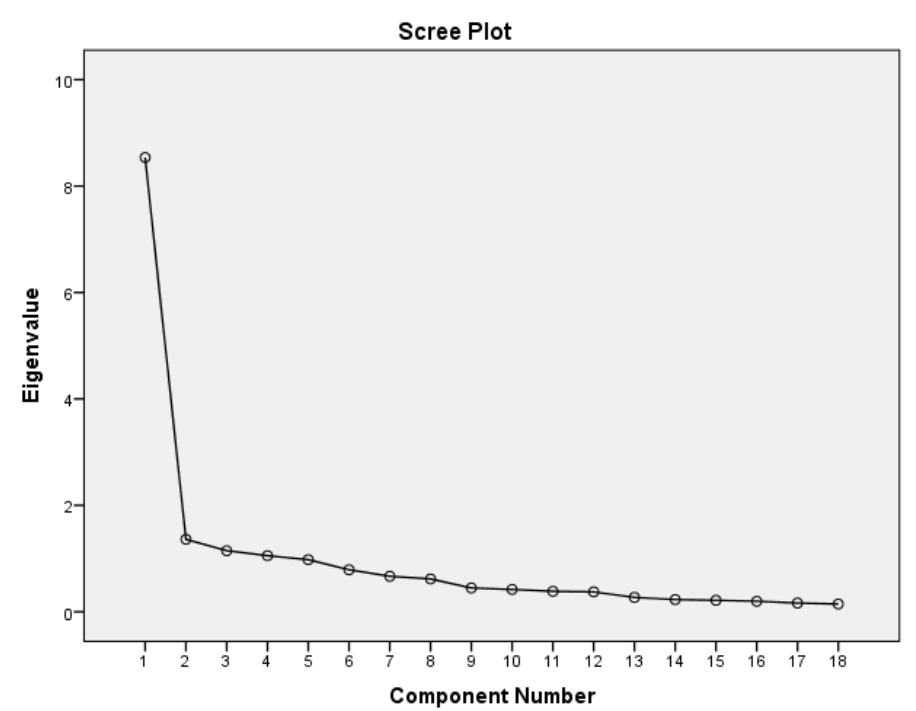

Figure 1. Scree plot

To determine the adequacy of the obtained structure, confirmatory factor analysis was performed on one factor. The results indicate that the one-factor model is well-suited to the data $(\chi 2 / \mathrm{df}<3$, RMSEA $=.103, \mathrm{CFI}=.877, \mathrm{SRMR}=.080)$. Since the values fit indices are within the range of the acceptable values $(\mathrm{Hu}$, Bentler, 1999; Tabachnick, Fidell, 2007) we conclude that confirmatory factor analysis confirmed the obtained structure.

Internal reliability of the test was very high $(\alpha=.93)$ which indicates good internal homogeneity of the test. We also performed split-half analysis of reliability with Spearman-Brown prediction formula, and all indicators suggest good reliability of the test (Table 2).

Table 2. Results of split-half analyses of reliability

\begin{tabular}{|c|c|c|c|}
\hline \multirow{5}{*}{ Cronbach's Alpha } & \multirow{2}{*}{ Part 1} & Value & .882 \\
\hline & & $\mathrm{N}$ of Items & $9^{\mathrm{a}}$ \\
\hline & \multirow{2}{*}{ Part 2} & Value & .889 \\
\hline & & $\mathrm{N}$ of Items & $9^{b}$ \\
\hline & \multicolumn{2}{|c|}{ Total $\mathrm{N}$ of Items } & 18 \\
\hline \multicolumn{3}{|c|}{ Correlation Between Forms } & .785 \\
\hline \multicolumn{3}{|c|}{ Spearman-Brown Coefficient } & .879 \\
\hline
\end{tabular}

a. The items are: q1, q2, q3, q4, q5, q6, q7, q8, q9.

b. The items are: q10, q11, q12, q13, q14, q15, q16, q17, q18.

The Digital Competency Test consisted of 18 questions, with the score being weighted depending on their difficulty and the number of actions that participants had to perform to find the correct answer. The point test range was from 0 to 40 (Table 3). A total of 11 respondents did not score a single point in the Digital Competence Test. These respondents are mostly female elementary school graduates, currently unemployed. They generally do not possess a personal computer in their household and state that they rarely use one.

The average score on the Digital Competence Test is in the middle of the theoretical range of scores on the test $(M=20.55)$, and we can conclude that on average, the participants have correctly solved about half of the test. The highest percentage of correct answers was on questions related to the use of e-mail technology (Table 4). The most incorrectly answered questions were those related to the usage of Excel. Also, the task of requiring the attendees to find the official web site of the Government of the Republic of Croatia was rarely answered correctly.

The results of the t test show that men and women do not differ significantly in their success on the Digital Competence Test $(\mathrm{t}=-1.39, \mathrm{df}=88, \mathrm{p}>.05)$. The result of the digital competence test is also not related to the age of the participants $(p>0.05)$. There was a statistically significant moderate 
correlation between the level of education and the year of completion of the last degree of education with the result on the Test. The result in the digital competence test was higher for people with higher the level of education $(\mathrm{r}=.341, \mathrm{p}<.01)$ and those who completed the education more recently $(\mathrm{r}=.296$, $\mathrm{p}<.01)$

Table 3. Descriptive statistics of results in The Digital Competence Test

\begin{tabular}{|l|l|l|l|l|l|l|l|l|l|}
\hline Variable & N & Min & Max & M & SD & SE & C & Q1 & Q3 \\
\hline $\begin{array}{l}\text { Results in } \\
\text { The Digital } \\
\text { Competence } \\
\text { Test }\end{array}$ & 92 & 0 & 40 & 20.55 & 13.629 & 1.421 & 7 & 7 & 33 \\
\hline
\end{tabular}

Table 4. Results on questions in The Digital Competence Test

\begin{tabular}{|c|c|c|c|}
\hline \multirow{2}{*}{ Question in test } & \multirow{2}{*}{ Score in test } & incorrect & correct \\
\hline & & $\%$ & $\%$ \\
\hline Win - document size & 2 & $45,70 \%$ & $54,30 \%$ \\
\hline Win - type of file & 2 & $63,00 \%$ & $37,00 \%$ \\
\hline Win - e-mail entry & 2 & $27,20 \%$ & $72,80 \%$ \\
\hline Win - Outlook (responding to e-mail) & 1 & $22,80 \%$ & $77,20 \%$ \\
\hline Word - font size & 1 & $37,00 \%$ & $63,00 \%$ \\
\hline Word - word count & 1 & $42,40 \%$ & $57,60 \%$ \\
\hline PowerP - number of slides & 1 & $50,00 \%$ & $50,00 \%$ \\
\hline Internet - Govt. e-mail address & 2 & $72,80 \%$ & $27,20 \%$ \\
\hline Internet - web page recognition & 1 & $25,00 \%$ & $75,00 \%$ \\
\hline Win - File's modification date & 2 & $43,50 \%$ & $56,50 \%$ \\
\hline Win - calculator & 3 & $46,70 \%$ & $53,30 \%$ \\
\hline Word - copy-paste & 3 & $34,80 \%$ & $65,20 \%$ \\
\hline Excel - Locating Sheet1 & 3 & $48,90 \%$ & $51,10 \%$ \\
\hline $\begin{array}{l}\text { Internet - mail address University of } \\
\text { Zagreb }\end{array}$ & 3 & $51,10 \%$ & $48,90 \%$ \\
\hline Excel - AutoSum & 4 & $64,10 \%$ & $35,90 \%$ \\
\hline Internet - locating e-mail address & 4 & $52,20 \%$ & $47,80 \%$ \\
\hline Internet - Google Maps - distance & 3 & $48,90 \%$ & $51,10 \%$ \\
\hline Win/Int - Uploading the file & 2 & $46,90 \%$ & $53,10 \%$ \\
\hline
\end{tabular}

Table 5. shows the correlations of the digital competence test and the digital skills self-assessment. Correlations are moderate, the highest one being with self-reported Word skills. The overall selfassessment of digital skills is moderately correlated with the score on the digital competence test (.599). The two measures share $35.8 \%$ of the total variance, which proves that the digital skills measure yields a unique variance through the knowledge test.

Table 5. Correlation between Results in The Digital Competency Test and self-assessment of digital skills

\begin{tabular}{ll}
\hline & Results in The Digital Competency Test \\
\hline Windows & $.554^{* *}$ \\
Word & $.630^{* *}$ \\
Excel & $.511^{* *}$ \\
PowerPoint & $.433^{* *}$ \\
Internet browser & $.544^{* *}$ \\
Internet banking & $.498^{* *}$ \\
Buying on the internet & $.344^{* *}$ \\
General grade of computer knowledge & $.599^{* *}$ \\
\hline
\end{tabular}




\section{Discussion and conclusion}

The one component structure of the Digital Competence Test suggests that the test measures general digital skill and can be used for its initial detection of digital competences level. The purpose of the test was not to verify or establish the structure of the construct of "digital literacy" or "digital skill", but rather to be a simple and reliable measure of general digital skill, measured through several most widely used computer technologies. In this respect, the test was successful given the special target population it was performed on. Apart from adult learners with low digital skills, the test could be used to detect the level of digital skills in other vulnerable groups (unemployed, minority groups, etc.) The significant result of this research is that almost $10 \%$ of the test takers didn't possess even the most basic digital skills and could not use the personal computer at all. As stated before, this group consists mainly of low educated women. This is hardly surprising since in Croatia there are $48 \%$ of males with basic or above basic digital skills, but only $34 \%$ of corresponding females (Eurostat, 2018). The situation is similar with respect to education. There are less than $20 \%$ of regular computer users with basic education, compared to around $80 \%$ of those with higher education (Državni zavod za statistiku Republike Hrvatske, 2018). None of the programs the respondents involve any type of digital skills instruction, which leaves these individuals without even basic digital skills even though it will certify them with the vocational education diploma. This situation is expected to be amended with the new curriculum for adult education in Croatia where digital skills will be treated as transversal skills.

The problems that have been unanswered the most (type of files, Excel, government web page) reflect the interests of the participants and their most frequent use of digital technologies. The participants use the technologies mostly for job hunting, information and leisure (data not shown). These activities rarely include technologies such as Excel, the technicalities like file size, type and location, and internet pages outside of their interest. The patterns of how respondents use digital technologies and consequently display digital skills can be explained by the differences between "lifestyle" and "workplace" skills. The skills adopted through the use in the lifestyle domain do not automatically transfer to the productivity or workplace domain (ECDL Foundation, 2018).

The observed difference in digital skills between the individuals of different levels of education is expected, given the experience in technology use the higher educated individuals gain through education and more complex jobs. It also might reflect the phenomenon of the "second digital divide" (Hargittai, 2002). While the original notion of "digital divide" emphasized the difference in access to digital technology between the social groups ("haves" and "have-nots"), the "second digital divide" posits that the difference is no more in the access to technology, but in the skills and motivation to use it (Hargittai, 2002). The technology like computers, smartphones, tablets, etc. have become accessible even to the poor and low educated individuals, but not the skills needed to embrace the full potential of participating in a digital society. On the methodological side, this result points to the convergent validity of the test since the difference in digital skills between different education groups are expected both from the theory and the past research.

The significant correlations between the self-assessment of the skills and their measured levels support Hargittai's assertion that self-assessment can be used as an indicator of real digital skills (Hargittai, 2005), yet the Digital Competence Test brings the unique variance that cannot be explained by the self-assessment alone. The answer to the question of why the self-assessment is positively correlated with the measured skills is outside the scope of this article and should be investigated separately. However, the uniqueness of the studied sample points to the possible answer. The subjects tested in this study are a part of a selected group of those who decided to educate themselves further or to change their profession altogether, to have better prospects of finding a job both in Croatia or abroad. Personal characteristics of the subjects may account for the correlation between selfassessment and real score. Those who have low digital skills are aware of it and do not exaggerate their self-assessment, as much as are aware of those with higher digital skills. It is possible that both groups high motivation and the dedication to learning prevent them from making exaggerated or false self-assessment claims.

As noted above, this research is relevant for testing the digital skills of adult learners and other subpopulations. Given the problems were conceived as real-life tasks of problem-solving through 
digital technology, the test can be expanded with other programs and more complicated problems tailored for the specific groups and their life experiences. It should be noted, however, that the results of this research have their shortcomings. The sample is not a probabilistic one and the number of participants is rather limited. The studied group is a specific one, unrepresentative of the general population, and some aspects of digital literacy (e.g. ethical aspect) have been omitted on purpose. The test should be applied to more groups to ensure its reliability and validity. The last point is also the direction for further research. If proven reliable and valid on other social groups, the test could be widely used as a simple and easy-to-implement initial screening tool for digital skills.

\section{References}

Chinien, C., Boutin, F. (2011). Defining Essential Digital Skills in the Canadian Workplace: Final Report. Montreal

Državni zavod za statistiku Republike Hrvatske. (2018). Statistički ljetopis Republike Hrvatske 2018 [Statistical Yearbook of the Republic of Croatia 2018]. Zagreb

ECDL Foundation. (2018). Perception \& Reality-Measuring Digital Skills Gaps in Europe, India and Singapore. http://ecdl.org/media/perception_reality_report___ecdl_foundation_-_2018_1.pdf (12.8.2019)

European Parliament and the Council of the European Union. (2006). Recommendation of the European Parliament and of the Council of 18 December 2006 on key competences for lifelong learning. Official Journal of the European Union, L 494, 10-12

Eurostat. (2018). Eurostat-Tables, Graphs and Maps Interface (TGM) table. https://ec.europa.eu/eurostat/tgm/refreshTableAction.do?tab=table\&plugin=1\&pcode=tepsr_sp410\&language=en (12.8.2019)

Ferrari, A. (2012). Digital Competence in practice: An analysis of frameworks. https://ictlogy.net/bibliography/reports/projects.php?idp=2263 (12.8.2019)

Fraillon, J., Ainley, J., Schulz, W., Friedman, T., Gebhardt, E. (2014). Preparing for Life in a Digital Age: The IEA International Computer and Information Literacy Study International Report

Gilster, P. (1997). Digital Literacy. New York: John Wiley and sons

Gui, M. (2007). Formal and substantial Internet information skills: The role of socio-demographic differences on the possession of different components of digital literacy. // First Monday 12, 9

Gui, M., Argentin, G. (2011). Digital skills of internet natives: Different forms of digital literacy in a random sample of northern Italian high school students. // New Media \& Society 13, 6, 963-980.

Halász, G., Michel, A. (2011). Key Competences in Europe: Interpretation, policy. // European Journal of Education 46, 3, 289-306

Hargittai, E. (2002). Second-Level Digital Divide: Differences in People's Online Skills. // First Monday 7, 4

Hargittai, E. (2005). Survey Measures of Web-Oriented Digital Literacy. // Social Science Computer Review, 23, 3, 371-379

Hargittai, E., Hinnant, A. (2008). Digital Inequality: Differences in Young Adults' Use of the Internet. // Communication Research 35, 5, 602-621

Hu, L., Bentler, P. M. (1999). Cutoff criteria for fit indexes in covariance structure analysis: Conventional criteria versus new alternatives. // Structural Equation Modeling: A Multidisciplinary Journal 6, 1, 1-55

Jara, I., Claro, M., Hinostroza, J. E., San Martín, E., Rodríguez, P., Cabello, T., Ibieta, A., Labbé, C. (2015). Understanding factors related to Chilean students' digital skills: A mixed methods analysis. // Computers \& Education 88, 387-398

Kaiser, H. F. (1970). A second-generation little jiffy. // Psychometrika, 35, 4, 401-415

Kirsch, I., Yamamoto, K., Garber, D. (2013). Chapter 1: PIAAC Assessment Design. // Technical Report of the Survey of Adult Skills (PIAAC). Paris: OECD, 1-42

Martin, A. (2008). Digital Literacy and the "Digital Society." // Digital Literacies: Concepts, Policies and Practices / Lankshear C; Knobel, M; (eds.) New York: Peter Lang Publishing, 151-176

Martin, A., Grudziecki, J. (2006). DigEuLit: Concepts and Tools for Digital Literacy Development. // Innovation in Teaching and Learning in Information and Computer Sciences 5, 4, 249-267

Merritt, K., Smith, K. D., Renzo, J. C. D. (2005). An Investigation of Self-Reported Computer Literacy: Is it Reliable? // Issues in Information Systems 7, 289-295

Sparks, J. R., Katz, I. R., Beile, P. M. (2016). Assessing Digital Information Literacy in Higher Education: A Review of Existing Frameworks and Assessments with Recommendations for Next-Generation Assessment: Assessing Digital Information Literacy in Higher Education. ETS Research Report Series 2, 1-33

Tabachnick, B. G., Fidell, L. S. (2005). Using multivariate statistics. 5th ed. Boston: Pearson/Allyn \& Bacon

van Deursen, A. J. A. M., Helsper, E. J., Eynon, R. (2016). Development and validation of the Internet Skills Scale (ISS). // Information, Communication \& Society, 19, 6, 804-823

van Deursen, A. J. A. M., van Dijk, J. A. G. M.; Peters, O. (2011). Rethinking Internet skills: The contribution of gender, age, education, Internet experience, and hours online to medium- and content-related Internet skills. // Poetics 39, 2, 125144

van Deursen, A. J. A. M., van Dijk, J. A. G. M. (2014). The digital divide shifts to differences in usage. // New Media \& Society, 16, 3, 507-526

van Deursen, A. J. A. M., van Dijk, J. A. G. M. (2008). Using Online Public Services: A Measurement of Citizens' Operational, Formal, Information and Strategic Skills. // Electronic Government / Wimmer, M. A., Scholl, H. J., Ferro, E. (eds.) Berlin: Springer, 195-206 